\title{
EL DEBIDO PROCESO Y LAS LINEAS CARDINALES \\ PARA UN MODELO PROCESAL EN EL ESTADO CONSTITUCIONAL DE DERECHO
}

\author{
Víctor Ticona Postigo*
}

\begin{abstract}
Resumen:
El Estado de Derecho deviene del Estado Legislativo o Estado basado en la ley, cuyo elemento esencial, entre otros, es la tutela jurisdiccional efectiva de todos los derechos y libertades; en esta perspectiva el autor hace una reseña sobre la evolución de la denominación de Estado de Derecho; explica sobre la tutela jurisdiccional y debido proceso como derechos fundamentales; si ambos derechos tienen relación de identidad o son diferentes; expone también su propuesta al respecto; y finalmente trata del reconocimiento de estos dos derechos en el derecho positivo Peruano.
\end{abstract}

Palabras Clave: Tutela Jurisdiccional - Estado de Derecho - Debido Proceso.

\begin{abstract}
A bstract:
The Government of laws comes from the Legislative State, whose essential element, among others, is the effective jurisdictional custody of all the rights and liberties; in this perspective the author inspects the evolution of the denomination of Government of laws; he explains the jurisdictional custody and the due process like fundamental rights; if both rights have identity relation or are different; it also exposes his proposal on the matter; and finally it deals with the recognition of these two rights in the Peruvian Law.
\end{abstract}

Key words: Effective Jurisdictional Custody - Government of law Due process.

\section{Sumario:}

1. Un modelo procesal eficaz y eficiente. 2. Estado de Derecho y Estado Constitucional de Derecho. 3. Los elementos cardinales de un modelo procesal para una tutela jurisdiccional efectiva. 4. Conclusiones.

* Vocal Supremo Titular. Presidente de la Sala Civil Transitoria de la Corte Suprema de Justicia de la República y profesor de la Universidad de Lima. 
Víctor Ticona Postigo - El debido proceso y las líneas cardinales para un modelo procesal en el Estado Constitucional de Derecho

En el marco deun Estado Constitucional deDerecho, como el que proclama nuestra Carta Política, se exige un modelo procesal que de modo efectivo haga realidad los derechos fundamental es y material es, los valores y fines prometidos por las Constitución. Este modelo procesal debe apuntar a asegurar, entre otras cosas, un mínimo de garantías procesales de rango constitucionales así como la realización de aquellos derechos, valores y fines, particularmente el valor justicia, que viene a configurar el valor supremo del derecho. ${ }^{1}$

\section{UN MODELO PROCESAL EFICAZ Y EFICIENTE}

Las urgentes exigencias de justicia eficaz y eficiente de nuestra comunidad imponen la necesidad no solamente de reconocer en el sistema jurídico procesal sino deformular un model o procesal queresponda a tales exigencias y urgencias.

Un modelo procesal tiene una operatividad en un espacio y en un tiempo determinado. Por ello es necesario reconocer que, en el presentey para nuestra sociedad, debe buscarse una fórmula procesal que se ubique en el contexto de un sistema jurídico-político, por lo menos reconocido formal mente por nuestra Constitución y proyectando los tipos de tutela básicos que debe prover.

A este efecto, será necesario, primeramente precisar si nuestro sistema constitucional responde o no a las características básicas de lo que se denomina un Estado Constitucional de Derecho.

Por otra parte, un modelo procesal será eficaz y eficiente según el tipo de tutel a que debe concretar. En este sentido es necesario distinguir, la Tutela Ordinaria dela Tutela Diferenciada, y cómo es queel modelo procesal debe variar en atención al tipo detutel a a cual debeservir deinstrumento y, como consecuencia de ello, podemos transitar de un modelo "plenamente garantista" a un modelo "mínimamente garantista".

Finalmente, será necesario responder a la pregunta ¿qué tipo de modelo procesal puede ser el más eficiente y eficaz desde la perspectiva constitucional? A quí será necesario revisar los conceptos tutela jurisdiccional efectiva, debido proceso, tutela procesal efectiva, entre otros. 
Víctor Ticona Postigo - El debido proceso y las líneas cardinales para un modelo procesal en el Estado Constitucional de Derecho

En resumen, consideramos quees necesario, entre otros, aspectos, relacionar y conjugar categorías como: Estado de Derecho y Estado Constitucional de Derecho; Tutela Jurisdiccional Ordinaria y Tutela Jurisdiccional Diferenciada; Debido Proceso, Tutela Jurisdiccional Efectiva y Tutela Procesal Efectiva. Como resultado de todo ello concluir cuáles serían las características esenciales que podría tener un modelo procesal en un Estado deDerecho como el nuestro. Por último, en esta primera parte, y desde ahora es pertinente preguntarse ¿Es el debido proceso, el modelo procesal que correspondeal Estado Constitucional de Derecho?

\section{ESTADO DE DERECHO Y ESTADO CONSTITUCIONAL DE DERECHO}

La denominación Estado de Derecho, ha tenido una evolución en la doctrina y en los sistemas jurídico-políticos.

En una primera concepción Estado de Derecho significa vinculatoridad a la ley, es decir que denota la sujeción a la ley detod os quienes ejercen autoridad y poder así como sujeción de los particulares en general. Se concibe como oposición al Estado absoluto, y como limitación y control del poder político “...la idea de un gobierno de leyes y no de hombres se sustancia a través de la sujeción a la Ley tanto de autoridades como de particulares; ciertamente ligado a ello, semencionan otros el ementos como los derechosfundamentales y la división de poderes, la primacía de la ley en el sistema de fuentes, la legalidad de la administración". ${ }^{2}$

En esta concepción se entiende a la ley en su sentido formal, esto es aquella norma jurídica expedida por el parlamento, depositaria de la voluntad del pueblo, siguiendo el procedimiento legislativo respectivo. Asímismo debe destacarseaquí quela ley ocupa el vérticesuperior detodo el sistemajurídico, por ello es válido afirmar que “...el Estado de Derecho deviene, más bien, en un Estado Legislativo o Estado basado en la Ley (formal). Resulta fuera de este contexto Ia Constitución, la inexistencia de mecanismos jurídicos (procesales) que tuvieran por objetivo directo proteger su supremacía en el sistema de fuentes, la excluyen de ser considerada un auténtico modo de producción del derecho, lo cual no supone desconocer, por una parte, la existencia de mecanismos políticos de tutela dela Constitución, ni por otra, la ubérrima experiencia norteamericana de la judicial review ya a partir de 1808; pues, eseno fueel contexto en el queel concepto deEstado de Derecho 
Víctor Ticona Postigo - El debido proceso y las líneas cardinales para un modelo procesal en el Estado Constitucional de Derecho

recibió su tratamiento teórico, sino el ámbito germano donde tal concepto el Rechsstaat- lo adquirióy, allí, el centro de preocupación teórica y dogmática (y entonces jurisprudencial) no fue la protección jurídica de la Constitución sino de la Ley, a cuyo efecto se orientan técnicas como el principio de legalidad, la reserva de la ley, la legalidad de la administración". ${ }^{3}$

En otra concepción encontramos que Estado de Derecho significa vinculatoriedad al Derecho por parte de quienes ejercen el poder político como de todos los particulares, entendiéndoseaquí quederecho no sereduce a la Ley formal expedida por el Parlamento sino que comprende a la Constitución y demás normas infraconstitucionales, como la ley y normas con rango legal así como las demás normas del Ejecutivo y de otros órganos integrantes del sistema defuentes. Aquí, la Constitución no solamente ocupa formalmente el vértice superior del ordenamiento jurídico sino que esencial mentetienesuprema fuerza normativa, quevincula a las autoridades y particulares. Por consiguiente, en esta concepción de habla de Estado Constitucional deDerecho.

En la doctrina se ha establecido algunas notas características de la Constitución del Estado Constitucional de Derecho:

a. Es una Constitución rígida o formal, en donde las disposiciones constitucionales tienen una calidad supralegal y su modificación no puedehacerse sino a través de un procedimiento especial y distinto a la de la norma legal ordinaria.

b. La Constitución responde a las pretensiones normativas del constitucional ismo político: la limitación del poder político y la garantía de los derechos. El ejercicio del poder político debe hacerse de modo institucionalizado y desde ciertos valores y fines, los cuales además tienen un carácter regulativo; para ello incorpora forma básicas para la acción jurídica (medios y formas para erradicar la arbitrariedad en el ejercicio del poder, el autoritarismo), propias de un Estado de Derecho; y, así como para la acción política (medios y formas para erradicar la exclusión política y social) propias de un Estado Democrático y Social deDerecho.

c. Esta Constitución formal además de responder a los lineamientos del constitucionalismo tien equeser practicada, es decir quetiene que haberse 
Víctor Ticona Postigo - El debido proceso y las líneas cardinales para un modelo procesal en el Estado Constitucional de Derecho

“...consolidado una práctica jurídica y política que permita afirmar que de hecho en torno a la Constitución formal se ha producido la estabilización de las conductas jurídicas y políticas de la comunidad de referencia, de forma que ella pueda ser considerada como norma fundamental $y$, en consecuencia, desempeña su papel en los problemas de identificación, de unidad y de continuidad del sistema jurídicopolítico". ${ }^{4}$

Por otra parte también se ha considerado en la doctrina ${ }^{5}$ como elementos esenciales del postulado del Estado de Derecho: a) La justicia y seguridad jurídica, b) La constitución como norma suprema, c) La división de poderes, d) La protección de los derechos fundamentales, e) La vinculación de los poderes públicos al derecho, a la ley, f) La tutela judicial y vertiente procedimental delos derechos fundamentales. A los cual esse podría agregar, el control jurisdiccional de los actos de la administración, el control de la constitucionalidad delas leyes, entre otros.

Nuestra Constitución, más allá delos cuestionamientos formales que pueden razonablemente hacerse, puede ser reconocida como una Constitución que pretende proponernos un sistema político-jurídico que tienecaracterísticas de un Estado Constitucional de Derecho ${ }^{6}$.

Encontramos quees una Constitución formal y rígida, quetiene pretensiones normativas ambiciosas del constitucional ismo político. Se puede sustentar Ia exigencia de derechos fundamentales implícitos a partir del Estado Democrático de Derecho (Art. $3^{\circ}$ ); quienes ejercen el poder lo hacen con "...la limitaciones y responsabilidades que la Constitución establecen (Art. 45o primer párrafo); todos, esto es autoridades y particulares, tienen el deber de respetar, cumplir y defender la Constitución y el ordenamiento jurídico (Art. 38\%). El Estado garantiza la plena vigencia de los derechos humanos así como la protección de la población de amenazas contra su seguridad. El Congreso tiene la atribución de velar por “...el respeto de la Constitución y delas leyes, y disponer lo conveniente para hacer efectiva la responsabilidad de los infractores" (Art. 102 inc. 2). Es atribución del Presidente de la República "Cumplir y hacer cumplir la Constitución y los tratados, leyes y demás disposiciones legales" Art. $118^{\circ}$ inc. 1). Por otra parte, con relación al capítulo del Poder Judicial se prevé que la función jurisdiccional se ejerce "con arreglo a la Constitución y a las leyes" (Art.138 , primer párrafo). Constituye atribución del Tribunal Constitucional el "control de la 
Víctor Ticona Postigo - El debido proceso y las líneas cardinales para un modelo procesal en el Estado Constitucional de Derecho

Constitución" (Art. $201^{\circ}$, primera parte). Los altos funcionarios de la Nación pueden ser sometidos a acusación constitucional por infracción a la Constitución o por cualquier otro delito cometido en ejercicio de sus funciones (A rt. 990 y 1009). Como principios y deberes de la función jurisdiccional se establecen una serie normas en el Art. 1390, y dentro de ellas la observancia del debido proceso y la tutela jurisdiccional (A rt. 139o inc. 3). Así mismo, se establece el principio dejerarquía normativa (Art. 51o parte final, 138 párrafo final ), entre otras normas.

Sin embargo, con relación a la tercera característica, la práctica jurídica y política en torno a la Constitución formal, podríamos afirmar, sin lugar a dudas, que no ha existido ni existerealmente dicha práctica casi permanente que permita concluir que se ha producido en la comunidad, y especial mente en los detentadores del poder público, una conducta y actitud sostenida y sincera de considerar a la Constitución como norma fundamental que le da unidad y continuidad a nuestro sistema jurídico-político.

Sabemos bien que nuestra vida republicana ha tenido period os de vigencia relativa de una democracia formal y, en otros periodos, de quebrantamiento de ésta como resultado de rupturas del orden constitucional (Ios denominados golpes o autogolpes de Estado). En consecuencia, se ha intentado, por lo menos formal mentey en periodos cortos de nuestra historia, la propuesta y la vigencia de un Estado de Derecho, y en las últimas décadas (Cartas Políticas de 1979 y 1993) de un Estado Constitucional de Derecho.

Desde otra perspectiva, como se ha anotado, en la doctrina también se considera que un elemento esencial del Estado de Derecho es la tutela judicial de los derechos fundamentales. Nosotros diríamos que dicho elemento está configurado por la tutela jurisdiccional efectiva de todos los derechos y libertades, y dentro de ellos y especialmente de los derechos fundamentales.

Pero una tutela jurisdiccional efectiva requiere, entre otras cosas, un proceso con un "mínimo de garantías" que hagan posible un juzgamiento justo e imparcial. Si el proceso es un instrumento detutela de los derechos materiales, y dentro de éstos los derechos fundamentales, podemos convenir que el proceso debetener, a su vez, una protección o tutela reforzada y decarácter constitucional. Hay que dar seguridad y garantías al proceso para que éste no sea el sepulcro de la justicia. El legislador, mediante leyes ordinarias 
Víctor Ticona Postigo - El debido proceso y las líneas cardinales para un modelo procesal en el Estado Constitucional de Derecho

procesales, puedehacer del proceso un instrumento ineficaz y frustrantede la tutela de los derechos, como cuando diseña un instrumento procesal que no garantiza a las partes una oportunidad para ser oído o para probar sus alegaciones. Así mismo, el juez, por su parte, también puede vulnerar el derecho a un proceso con "mínimo de garantías" cuando omite proveer un pedido del abogado del litigante para informar oral mente antes de resolver el fondo de la controversia. El mismo agente administrativo, cuando en un procedimiento administrativo sancionador impone una sanción disciplinaria a un administrado sin motivación alguna o con una motivación aparente.

Que, como consecuencia de los horrores producidos en la Segunda Guerra Mundial, los derechos fundamental es empezaron a tener un rol vital en los sistemas democráticos. No era suficiente la elaboración de leyes mediante un procedimiento formal como expresión de la voluntad de las mayorías, también era absolutamente necesario el respeto a las sustancias democráticas encarnadas por los derechos fundamentales. Establecidos por Convenciones Constituyentes el egidas democráticamente, instituían un límite a voluntad absoluta de las mayorías, las cuales no podían actuar violentando los derechos fundamentales. El derecho a la tutela judicial efectiva significa la potestad de acceder a los órganos jurisdiccional es con el fin de defender los derechos subjetivos y colectivos. El sujeto activo de este derecho es el justiciable, y el sujeto pasivo es el Estado mediante el Juez encargado de administrar justicia. Este derecho esta relacionado con el principio pro accione el cual establece que el órgano judicial realice un juicio objetivo y fundado respecto a la verosi militud dela pretensión solicitada y dela acción que la viabiliza, de forma que el exceso de rigor procesal asfixie el sistema de derechos ${ }^{7}$.

La definición de legitimidad del poder político y delas instituciones por las cuales se gobierna un Estado, son de gran importancia en la Ciencia Política contemporánea. Aunque el principio del debido proceso como tal no garantiza la rectitud de una norma, nos debemos remitir a los criterios materiales de legitimación como la idea dela justicia, para justificar el Estado de Derecho, pues si bien el criterio de legitimación formal constituido por ciertas garantías de orden procesal no es suficiente para la legitimación de un Estado, tiene un rol trascendente en la legitimación de la referida estructura de Estado ${ }^{8}$. 
Víctor Ticona Postigo - El debido proceso y las líneas cardinales para un modelo procesal en el Estado Constitucional de Derecho

Como señala A rturo Hoyos, existen cuatro tipos de bienes que tienen una importancia esencial en el desarrollo dela democracia: Ios derechos políticos, los derechos humanos, la libertad de expresión y de prensa y el acceso a la educación superior. Entre los derechos humanos más general es se incluyen: el derecho a la libertad frenteal arresto arbitrario y la posibilidad de accionar el hábeas corpus, el derecho a la no discriminación y la libertad de no sufrir abusos físicos; todo ello se encuentra directamente relacionado con la posibilidad de que las personas tengan acceso a la justicia y garantía de un debido proceso $0^{9}$.

Por tanto, en un Estado Constitucional de Derecho, en el que se inscribe nuestra vigenteConstitución, la tutela jurisdiccional efectiva, requiere, entre otros, de un proceso con un mínimo degarantías. Estetipo de proceso, para que no sea violentado por quienes ejercen el poder público (legislador, juez y administrador) y sea respetado en su verdadera dimensión por la comunidad y los justiciables, requiere que sea diseñado a partir de normas constitucionales, por eso podemos compartir, en principio y en un primer momento, la propuesta de Couture: hay que tutelar el proceso para queél a su vez pueda tutelar el derecho, a través de la "Tutela Constitucional del Proceso". ${ }^{10}$

Empero, nuestra propuesta va dirigida a postular una Tutela Supraconstitucional del Proceso, es decir, queel proceso como instrumento de realización de todos los derechos y dentro de ellos, claro está, los derechos fundamentales, sea a su vez protegidos a través de normas procesales cardinales, no solamente de carácter constitucional sino también, y final mente, de carácter supraestadual, como los Convenios, Tratados, Pactos, Declaraciones sobre Derechos H umanos, en los cuales nuestro Estado sea partey, por consiguiente, con vigencia efectiva y plena en territorio nacional. Esto importa reconocer a estos instrumentos internacionales, en los cuales Perú es parte, con el carácter de normas derango constitucional, tal como lo hacía la Constitución de 1979, pues la Constitución en vigencia solamente reconoce la jerarquía de norma legal a dichos instrumentos internacionales (Arts. 550 y $200^{\circ}$ inc. 4).

Como venimos advirtiendo, para que sea efectiva la tutela jurisdiccional, se requiere de un proceso con garantías mínimas. Esta necesidad no lleva a buscar y postular un model o procesal que responda a estas exigencias, pues sería vano reconocer derechos en la Constitución cuando ellos no pueden 
Víctor Ticona Postigo - El debido proceso y las líneas cardinales para un modelo procesal en el Estado Constitucional de Derecho

hacerse efectivos en un proceso jurisdiccional; por mucha razón Piero Calamandrei nos recordaba con preocupación: todas las libertades son vanas sino se les puede reivindicar y defender en proceso, si el individuo no encuentra ante sí jueces independientes, responsables y capaces.

Este modelo procesal, diseñado sólo en sus líneas cardinales, debe ser formulado y reconocido en la Constitución Política del Estado y en las leyes de desarrollo constitucional correspondientes.

\section{LOS ELEM ENTOS CARDIN A LES DE UN MODELO PROCESAL PARA UNA TUTELA JURISDICCIONAL EFECTIVA}

Nuestra Carta Política (A rt. 1399 inc. 3) ha reconocido el derecho a la tutela jurisdiccional y el debido proceso. Es entonces por demás pertinente preguntarse ¿se trata de dos derechos fundamentales o de un sólo derecho con distintas manifestaciones?

\subsection{CORRELACIÓN DE ESTOS DOS DERECHOS FUNDAMENTALES EN LA DOCTRINA NACIONAL}

En la doctrina y el derecho comparado no existe consenso sobre la relación entre estos dos derechos fundamentales. Para unos, son derechos de contenido idéntico, para otros, son derechos de ejercicio sucesivo y, finalmente para otro sector de la doctrina existe entre tales derechos una relación de interferencia de contenidos. Puede también sostenerse que son derechos que tienen su origen y vigencia en sistemas jurídicos distintos: el derecho a la tutela jurisdiccional tiene su origen en el derecho eurocontinental mientras que el debido proceso legal deorigen en el derecho anglosajón y, por tanto, serían derechos distintos, con propios contenidosy alcances.

La Tutela Judicial Efectiva tiene sus orígenes en la redacción del art. 24ㅇ de la Constitución Italiana de 1947 y en la elaboración de los artículos 19.4 y 103.1 de la Ley Fundamental de Bonn de 1949, siendo recogida también en el art. 24 de la Constitución española de 1978, que dio mayor difusión a esta institución. La mayor distinción entre Tutela Judicial española con los derechos constitucional es alemanes eital ianos citados, es que no ponetanto énfasis en garantizar la actividad impulsora o reaccional del ciudadano, 
Víctor Ticona Postigo - El debido proceso y las líneas cardinales para un modelo procesal en el Estado Constitucional de Derecho

sino que busca principal mente asegurar el tipo de respuesta que se obtiene del órgano judicial ${ }^{11}$.

En todo caso, en nuestro sistema jurídico nacional, ambos derechos son reconocidos explícitamente como derechos fundamentales, existiendo discrepancia sobre el contenido y al cances de cada uno de ellos. Veamos el planteamiento de estas posiciones.

\section{A. RELACIÓN DE IDENTIDAD O CONTENIDO UNÍVOCO}

A lgunos autores sostienen queel debido proceso es la expresión concreta del derecho a la tutela jurisdiccional efectiva, por cuanto este es un derecho abstracto pero que su concreción se plasma a través de aquel derecho fundamental. Sería algo así como que el derecho a la tutela jurisdiccional es la anatomía o la forma estática de ese derecho fundamental y el debido proceso como la fisiología o forma dinámica de aquel derecho. En consecuencia, según esta primera posición, setrataría deun sol o derecho que se expresa en forma estática y en forma dinámica; o bien, un mismo derecho fundamental que su expresión abstracta es denominada tutela jurisdiccional efectiva mientas que su expresión concreta es denominada debido proceso. En suma, el debido proceso sería instrumento para lograr una tutela jurisdiccional efectiva.

En esta línea de pensamiento se inscribe A níbal Quiroga León ${ }^{12}$, cuando afirma que "Vemos pues que el proceso judicial, en tanto D ebido Proceso, esel instrumento necesario para la obtención dela tutelajudicial a partir del cumplimiento de sus principales finalidades: el acceso al ideal humano de justicia, el otorgamiento de la necesaria paz social para el gobierno de los hombres en un Estado Democrático de Derecho y la solución concreta de las controversias intersubjetivas de los particulares dándose a cada uno lo que en derecho le corresponde(...)- y citando a Couture agrega - Por ello, el debido proceso (que ha de garantizar la correcta aplicación y vigencia del proceso judicial ), es a su vez garantía de una tutela judicial y ello, por su parte, el emento indispensable para la consecución de la finalidad del propio proceso judicial (...) es en esa virtud, que refuerza el concepto sosteniendo que el Debido Proceso, o derecho deA udiencia en juicio según la tradición española, comprende en sus aspectos procesales, numerosas instituciones relacionadas tanto 
Víctor Ticona Postigo - El debido proceso y las líneas cardinales para un modelo procesal en el Estado Constitucional de Derecho

con las partes como con la jurisdicción que han de preservar la certeza, obtención de una efectiva tutela judicial a partir del proceso".

Esta Relación de identidad también es compartida por Marcial Rubio Correa cuando sostiene que "De manera que lo más razonable en vista de la cercanía de los conceptos, es decir que el debido proceso y tutela jurisdiccional parecen ser en sustancia el mismo cuerpo de derechos que tiene dos nombres distintos por haber tenido dos procedencias distintas, tanto denaciones como defamilias del Derecho. Desdeel punto de vista de la Constitución debiera haber bastado con una de las alternativas en este inciso y, en tal caso, debería haberse el egido la de debido proceso que tiene mayor reconocimiento en el Derecho contemporáneo". ${ }^{13}$

Para Juan Monroy Gálvez ${ }^{14}$ el derecho a la tutela jurisdiccional efectiva es el derecho fundamental, del cual es titular cualquier persona por el solo hecho deserlo y quelo faculta para exigir queel Estado cumpla su función jurisdiccional. Ese derecho tiene dos planos deexistencia: antes y durante el proceso. Antes del proceso, el derecho a la tutela jurisdiccional es la potestad que permite exigir al Estado provea a la sociedad de los presupuestos o elementos necesarios, materiales y jurídicos para el desarrollo de un proceso judicial, como también afirma H oracio Rosatti ${ }^{15}$ por este derecho es posible exigir al Estado la existencia de una órgano público encargada dela resolución de los conflictos y queel mismo tenga una infraestructura adecuada y normas procesales que aseguren un tratamiento sencillo, didáctico y expeditivo al conflicto.

Durante el proceso, sostiene Monroy Gálvez ${ }^{16}$ el derecho a al tutela jurisdiccional contiene un haz de derechos esenciales que el Estad o debe proveer a todo justiciable que participe en todo proceso judicial y comprende dos derechos: derecho al proceso, en virtud del cual nadie puede ser condenado sin proceso judicial previo, y el derecho en el proceso, que sería el derecho al debido proceso; por tanto para Monroy el derecho a la tutela jurisdiccional es un derecho abstracto (anatomía del derecho) a partir de los derechos de acción y de contradicción; es decir, queel primero como dimensión abstracta del derecho fundamental $y$, el segundo, como dimensión concreta, en su ejercicio, del mismo derecho. A quél los se tratarían de un mismo derecho, pero expresado en dos aspectos: uno estático y otro dinámico. 
Víctor Ticona Postigo - El debido proceso y las líneas cardinales para un modelo procesal en el Estado Constitucional de Derecho

En esta misma vertiente se halla Fix Zamudio para quien el debido proceso es el conjunto de princi pios y presupuestos procesales mínimos que debe reunir todo proceso judicial para asegurar el justiciable la certeza, justicia y legitimidad de su resultado, por consiguienteel debido proceso sería la plasmación de la tutela jurisdiccional efectiva.

\section{B. DERECHOS DISTINTOS Y DE EJERCICIO SUCESIVO}

A lgunos autores consideran que el derecho a la tutela jurisdiccional y el debido proceso son derechos distintos pero que se ejercitan en forma sucesiva. En esta postura encontramos a Sáenz Dávalos quien sostiene que el derecho a la tutela jurisdiccional consiste en el derecho que tiene toda persona de acceder al órgano jurisdiccional por medio de la vía procesal correspondiente, por lo que su primordial manifestación es el derecho de acción; de tal forma que una vez iniciado el proceso lo que suceda en él o posteriormenteincumbeal debido proceso legal. Y según Juan Montero A roca, derecho deacción es previo al proceso, abstracto y público pues su destinatario es el Estado que activa la maquinaria judicial con imperium.

En consecuencia, según esta postura, el derecho a la tutela jurisdiccional que se manifiesta principalmente por el derecho de acción, es previo al proceso y lo activa, en tanto que el debido proceso tienelugar como un plexo de derechos quetiene existencia y su ejercicio se da en el desarroll o mismo del proceso. Por tanto, serían derechos de existencia y ejercicio sucesivo, primero el derecho a la tutela jurisdiccional, y ya dentro del proceso, el derecho al debido proceso legal. O como bien expone Ricardo Herrera Vásquez refiriéndose a esta posición" Así, estaríamos ante dos principios de ocurrencia sucesiva: la tutela judicial efectiva se da antes de ini ciarse el proceso, más aún lo activa, mientras queel debido proceso legal interviene en el desarrollo del proceso mismo".

\section{NUESTRA PROPUESTA: RELACIÓN DIALÉCTICA O DE MUTUA RELACIÓN}

En otra vertiente consideramos que los derechos a la tutela jurisdiccional y al debido proceso se relacionan mutuamente, en el sentido de que una parte del debido proceso tiene su vigencia dentro del ámbito 
Víctor Ticona Postigo - El debido proceso y las líneas cardinales para un modelo procesal en el Estado Constitucional de Derecho

jurisdiccional y, a su vez, una parte del derecho a la tutela jurisdiccional tiene su vigencia conjuntamente con el debido proceso.

Como se ha reconocido ampliamente en la doctrina, el debido proceso tiene aplicación en los ámbitos jurisdiccional, administrativo y en el corporativo-particular; por consiguiente, solo una parte del debido proceso, o mejor aún, una de sus varias expresiones tiene lugar en el ámbito del proceso jurisdiccional.

Por otro lado, convenimos en Rosatti y M onroy queel derecho a la tutela jurisdiccional tiene lugar antes y durante el proceso judicial. Como ha quedado plenamente establecido en la doctrina, la jurisdicción, además deser un derecho y un imperium, es un deber del Estado. Y como correlato a este deber se encuentra el derecho que tiene toda persona a la tutela jurisdiccional efectiva. Juan Monroy Gálvez, citando además al profesor argentino Horacio D. Rosatti, opiniones que compartimos, conviene en que es factible ubicar el derecho a la tutela jurisdiccional antes y durante el proceso. "En el primer caso- nos dice Monroy Gálvez ${ }^{17}$ - el derecho a la tutela jurisdiccional antes de proceso consiste en aquel derecho que tiene toda persona, en tanto es sujeto de derechos, de exigir al Estado provea a la sociedad de los requisitos o presupuestos materiales y judiciales indispensables para solventar un proceso judicial en condiciones satisfactorias. Resulta absolutamente irrelevantesi esa estructura material y jurídica que debesostener el Estado va a ser usada o no. Lo trascendente es única y exclusivamente, que ese andamiaje destinado a solucionar conflictos aplicando el derecho que corresponde al caso concreto debe estar siempre en aptitud de conceder a los ciudadanos la posibilidad de un tratamiento certero, eficaz y homogéneo a su exigencia de justicia".

En el mismo sentido, Germán J. Bidart Campos ${ }^{18}$ afirma la existencia del derecho a la tutela jurisdiccional antes del proceso, como una etapa previa al proceso cuando expresa que el derecho a la jurisdicción es un supuesto de la actividad procesal que, en su primera etapa, aparece como se desenvuelveal hilo del proceso hasta la sentencia firme.

En el segundo caso, el derecho a la tutela jurisdiccional duranteel proceso consiste en el derecho quetiene toda persona de acceder a un proceso, a un juicio previo, con garantías mínimas que aseguren un juzgamiento imparcial y justo. 
Víctor Ticona Postigo - El debido proceso y las líneas cardinales para un modelo procesal en el Estado Constitucional de Derecho

Monroy Gálvez certeramente postula que el derecho a la tutela jurisdiccional duranteel proceso se puede desdoblar, teniendo en cuanta su contenido y momento de su exigibilidad, en derecho al proceso y derecho en el proceso. El primero es el derecho a juicio previo y, el segundo, es el denominado derecho al debido proceso legal o due process of law o proceso justo.

Cuando el Juez, en forma arbitraria e ilegal, rechaza liminarmente una demanda, evidentemente esta vulnerando el derecho a la tutela jurisdiccional, en su modalidad de derecho al proceso. En cambio, si el Juez sin motivo razonable, niega la oportunidad probatoria a cualquiera de las partes, esta lesionando el derecho a la tutela jurisdiccional, en su modalidad derecho en el proceso.

Duranteel proceso judicial, el derecho a la tutela jurisdiccional se expresa conjunta, paralela o simultáneamente, con el debido proceso. Por ello pensamos que el para los efectos del proceso judicial, el derecho a la tutela jurisdiccional es un derecho fundamental género $u$ omnicomprensivo que contiene, a su vez, los derechos también fundamentales: deacción, que correspondeal accionante (demandante, Ministerio Público, etc.); el derecho de contradicción, que corresponde al emplazado (o imputado en su caso); y el derecho al debido proceso, cuyos titulares son el accionand o y el demandado o imputado, lo mismo quetodos los terceros legitimados.

En resumen, nuestra propuesta radica en sostener que una parte del derecho a la tutela jurisdiccional tienelugar duranteel proceso judicial; y , así mismo una parte del debido proceso tiene presencia durante el referido proceso judicial, de tal forma que ambos derechos tienen una mutua relación, y dentro deesta mutua relación aún podemos distinguir que el derecho a la tutela jurisdiccional, dentro del proceso judicial despliega sus efectos en tres momentos sucesivos: el derecho de acceso al proceso y jurisdicción, el derecho al debido proceso y el derecho a la efectividad o eficacia de las sentencias y resoluciones homologatorias.

Aún más, creemos que el proceso justo, de manera integral y eficiente, comprende el debido proceso formal y el debido proceso sustantivo; puesto que, si el proceso judicial, cumpliendo ese mínimo de garantías procesales, tiene como epílogo una decisión o sentencia arbitraria y por 
Víctor Ticona Postigo - El debido proceso y las líneas cardinales para un modelo procesal en el Estado Constitucional de Derecho

tanto injusta, no hay debido proceso; así mismo, si la decisión es objetiva y materialmente justa, pero no se ha llegado a esta decisión cumpliendo ese mínimo de garantías, tampoco podrá sostenerse que se ha configurado un debido proceso.

Reynaldo Bustamante ${ }^{19}$ sostiene que el derecho fundamental a un proceso justo supone la vigencia efectiva de los derechos al debido proceso adjetivo procesal conjuntamente con el denominado debido proceso sustancial o sustantivo, pues sólo la concurrencia de ambos otorga a los justiciables una verdadera oportunidad para formular sus pretensiones, exponer su defensa, impugnar, probar y obtener una decisión justa en forma oportuna, efectiva y diferenciada dentro de un plazo razonable, criterio con el cual compartimos.

En las Bases Constitucionales mínimas del Proceso Civil "Justo" para A mérica Latina ${ }^{20}$, se define la relación entre jurisdicción y proceso del modo siguiente:

“1) Definición. La jurisdicción se ejerce y actúa mediante un proceso "justo" (o equitativo). Se considera "justo" todo tipo de proceso cuya garantías fundamentales sean reguladas por la ley, en el respeto pleno de los derechos inviolables del hombre y de conformidad con los principios establecidos en las siguientes normas", "5) Derecho a un juicio justo y público. Todos tienen derecho a que su asunto sea tratado, discutido y decidido equitativa y públicamente, en un plazo razonable de tiempo, frente a un juez independiente e imparcial, preconstituido por ley".

El debido proceso como instituto jurídico, de antiguo cuño, ha tenido una evolución en el tiempo y en los distintos sistemas jurídicos en donde fue acogido y adaptado; este instituto tiene proyecciones tanto en los sistemas internos como en los ordenamientos de carácter internacional . Ya es doctrina sentada por la CorteInteramericana de Derechos H umanos que toda persona tiene derecho a un recurso efectivo para hacer valer los derechos reconocidos en la Convención. La negación o inexistencia de estederecho constituye una omisión por el Estado parte. En consecuencia la Corte ha establecido la doctrina del derecho a un proceso con todas las garantías como expresión del debido proceso al que están obligados a brindar los Estados parte. ${ }^{21}$ 
Víctor Ticona Postigo - El debido proceso y las líneas cardinales para un modelo procesal en el Estado Constitucional de Derecho

Final mente cabe concluir queel model o procesal eficaz y eficienteen un Estado Constitucional de Derecho, puede concebirse de dos maneras: a) en sentido estricto, cuando la Constitución Política reconoce el ementos del debido proceso comunes a todo tipo de procesos, como el civil, penal, laboral, contenci oso-administrativo, defamilia, etc; b) en sentido amplio, cuando la Constitución además de reconocer aquellos elementos comunes del debido proceso exigibles en todo tipo de proceso jurisdiccional, también reconoce el ementos particulares para algunos procesos como es el caso del proceso penal en donde generalmente se reconoce elementos propios como el derecho a no autoinculparse o el derecho a no declarar o guardar silencio, etc. Nuestra Constitución Política vigentese adhierea una concepción en sentido amplio del debido proceso como modelo procesal de raigambre constitucional. En esta última perspectiva se ubica David Vallespín Pérez, que postula:

“De ahí que el modelo constitucional de proceso contenga, por una parte, un núcleo interrelacionado de el ementos constantes einsuprimi bles en todo procedimiento jurisdiccional establecido en el ordenamiento jurídico; y, por otra, un conjunto de características móviles y espacios vacíos destinados a ser variados y colmados por el legislador ordinario con el fin de al canzar los objetivos por él perseguidos. Surgeasí, lo que se ha dado en denominar, tanto a nivel nacional como supranacional, modelo de proceso justo" 22 .

\subsection{RECONOCIMIENTO DE ESTOS DOS DERECHOS EN EL DERECHO POSITIVO NACIONAL}

Como ya se ha visto, nuestra Carta Política (Art. 1390 inc. 3) reconoce a la tutela jurisdiccional y el debido proceso como principios de la función jurisdiccional. En esta norma constitucional no se establece si es un solo derecho o dos derechos, y en ésteúltimo caso, cuál sería el tipo de correlación entre ambos derechos.

La vigente Ley Orgánica del Poder Judicial reconoce(A rt. 70, primer párrafo) que "En el ejercicio y defensa de sus derechos, toda persona goza de la plena tutela jurisdiccional efectiva, con la garantías de un debido proceso". Encontramos que se establece un tipo derelación, aunqueen términos muy general es; pues se reconoce queel derecho a la tutela jurisdiccional efectiva debe concederse con todas las garantías de un debido proceso. 
Víctor Ticona Postigo - El debido proceso y las líneas cardinales para un modelo procesal en el Estado Constitucional de Derecho

El Código Procesal Civil, en el Art. I del Tít Prel. reconoce estos dos derechos y los relaciona del siguiente modo: "Derecho a la tutela jurisdiccional efectiva.- Toda persona tiene derecho a la tutela jurisdiccional efectiva para el ejercicio o defensa de sus derechos o intereses, con sujeción a un debido proceso". Este mismo cuerpo legal también habilita el recurso de casación cuando se ha contravenido las normas quegarantizan el derecho a un debido proceso (Art. 3860 inc. 3), y, por otro lado, regula el proceso de nulidad de cosa juzgada fraudulenta y lo habilita para el supuesto en que se alegue que “...el proceso que se origina ha sido seguido con fraude o colusión, afectando el derecho a un debido proceso, cometido por una, o ambas partes, o por el juez o por éste y aquéllas...".

La Ley del Procedimiento General (Ley 27444) en el Art. IV, numeral 1.2. reconoce como princi pio del procedimiento administrativo en denominado "Principio del debido procedimiento" y establece que los administrados gozan de todos los derechos y garantías inherentes al debido procedimiento administrativo, el cual comprende al derecho a exponer sus argumentos, a ofrecer y producir pruebas y a obtener una decisión motivada y fundada en derecho.

La ley sobreel Proceso Contencioso Administrativo en Art. 1으, cuando regula la finalidad, previene que la acción contencioso administrativa tiene por finalidad el control jurídico por el Poder Judicial de las actuaciones de la administración pública sujetas al derecho administrativo así como la efectiva tutela de los derechos e intereses de los administrados.

Por otra parte, el Código Procesal Constitucional prevé (Art. 4ํ) que procede el amparo contra resoluciones judiciales firmes con manifiesto agravio a la tutela procesal efectiva, el que a su vez comprende el derecho de acceso a la justicia y el debido proceso. El mismo cuerpo legal dispone (Art. 370 inc. 16) que el amparo procede en defensa del derecho de tutela procesal efectiva.

La Ley Procesal del Trabajo -Ley 26636- también reconoce el derecho a un debido proceso, en el art. I desu Título Preliminar, señalando queel proceso se realiza procurando queen desarrollo ocurra en el menor número deactos procesales, y queel Juez podrá reducir su número sin afectar la obligatoriedad de los actos que aseguren el debido proceso. 
Víctor Ticona Postigo - El debido proceso y las líneas cardinales para un modelo procesal en el Estado Constitucional de Derecho

\subsection{LA TUTELA JURISDICCIONAL EFECTIVA Y EL DEBIDO PROCESO EN LA JURISPRUDEN CIA NACIONAL}

Recordemos que la ley 23506, denominada ley de habeas corpus y amparo, disponía (Art. 5o) que es pertinente la acción de garantía si una autoridad judicial, fuera de un procedimiento que es de su competencia, emite una resolución judicial o cualquier disposición que lesiones un derecho constitucional; y así mismo, se establecía (Art. 60 inc.2) quees improcedente de las acción de garantía contra resolución judicial emanada de un procedimiento regular.

El Ilamado Tribunal de Garantías Constitucionales interpretando estas normas estableció que el procedimiento "irregular" no era otro que aquel proceso en donde se había contravenido el debido proceso.

El Tribunal Constitucional consideró igual mente que el proceso irregular es aquél en dondese infringió las normas del debido proceso, así en la sentencia emitida en el Exp. № 613-2003-AA/ TC de fecha 21-04-03 estimó que el proceso quese encuentra viciado de una absoluta irregularidad, pues el proceso de reivindicación se tornó en irregular desde mucho antes de la etapa de ejecución de sentencia.

Definiendo el debido proceso, el TC sostuvo que:

"El debido proceso está concebido como el cumplimiento de todas las garantías y normas deorden público que deban aplicarse a todos los casos y procedimientos existentes en el Derecho" (Sentencia de 16-10-02 emitida en el Exp.0751-2002-AA-TC).

En resoluciones sumamente claras el mismo TC estableció que el debido proceso forma parte del derecho a la tutel a jurisdiccional, además del derecho deacceso a la justicia y al derecho de efectividad delas resoluciones judiciales:

“(...) el derecho a la tutela jurisdiccional no sólo implica el derecho de acceso a la justicia y el derecho al debido proceso sino también el derecho a la efectividad de las resoluciones judiciales" (Sentencia de 06-12-02 emitida en el Exp. 1042-2002-AA-TC, acción de amparo iniciado por Miguel Cabrera León en contra de la Municipalidad Distrital del Rímac. 
Víctor Ticona Postigo - El debido proceso y las líneas cardinales para un modelo procesal en el Estado Constitucional de Derecho

“...En nuestro ordenamiento constitucional el derecho fundamental al debido proceso goza de una doble protección en lo que se refiere a los procesos constitucionales. En efecto, por un lado es pasi ble de ser tutelado a través del proceso constitucional de amparo, pero también a través del proceso constitucional de hábeas corpus. En el primer caso, es decir en el proceso de amparo, la tutel a procesal efectiva no exige necesariamente conexión con otro derecho fundamental a efectos de su protección, en el sentido del artículo 370 inciso 16, del Código Procesal Constitucional. En el segundo, por el contrario, el derecho fundamental a la tutela procesal efectiva precisa desu vinculación con el derecho fundamental a la libertad personal, en cuyo caso, el hábeas corpus, tal como dispone el artículo 25o inciso 17, del Código Procesal Constitucional, es el proceso constitucional idóneo para su protección..." (Sentencia del 29-08-2007 emitida en el exp. 02492-2007-HC/ TC, Habeas Corpus interpuesta por Lupe Cevallos Gonzáles en contra del Fiscal Provincial Titular especializado en Delitos de Tráfico llícito de drogas)

La Corte Suprema en forma progresiva ha ido perfilando una concepción sobre la tutela jurisdiccional efectiva y el debido proceso e igualmente identificando una serie de elementos. Recogiendo toda esta evolución, ha establecido y fijado los elementos del debido proceso:

“(...) el derecho a la tutela jurisdiccional efectiva tiene un contenido complejo y onmicomprensivo y que está integrado por el derecho de acceso a la jurisdicción y al proceso, el derecho al debido proceso y a la efectividad de las decisiones judiciales finales" “(...) "El debido proceso, en esta perspectiva, tiene dos dimensiones: una dimensión procesal, adjetiva o formal; y otra sustantiva o material. La dimensión procesal, a su vez, comprende otros derechos específicos, igual mente de carácter fundamental, como son: a) al procedimiento legal y previamenteestablecido; b) al juez determinado por la Constitución y predeterminado por la ley (Juez natural); c) a un emplazamiento válido en el ámbito del proceso civil, o a ser informado de la imputación o acusación en el ámbito del derecho penal; d) a ser oído o deaudiencia en lo civil, y a no ser condenado en ausencia en lo penal; e) a la defensa y asistencia de letrado; f) el derecho a la prueba; g) al uso del propio idioma y, en caso necesario, a intérprete; h) a no declarar contra sí 
Víctor Ticona Postigo - El debido proceso y las líneas cardinales para un modelo procesal en el Estado Constitucional de Derecho

mismo y a no confesarse culpable; i) a un proceso de duración razonable, sin dilaciones indebidas; j) a la presunción de inocencia; k) a la publicidad del proceso, salvo casos excepcionales; I) a que el juez que instruya o investiga sea distinto al que juzga o sentencia en lo penal; $m$ ) a una sentencia congruente, motivada en forma adecuada y suficiente; $\mathrm{n}$ ) a la instancia plural y control constitucional del proceso; o) a la prohibición de la reforma peyorativa, reforma en peor o "reformatio in peius"; p) a la cosa juzgada con un mínimo contenido dejusticia con carácter inmutable; q) a no ser juzgado dos veces por el mismo hecho: $\mathrm{Ne}$ bis in idem. En tanto, el debido proceso, en su dimensión material o sustantiva, exige que la decisión jurisdiccional sea razonable; y no obstanteesto, en atención a la característica delos Derechos Fundamentales que se ha venido en denominar de especificidad, progresividad y expansividad, debe interpretarse que el debido proceso en su dimensión material exige una sentencia jurisdiccional objetiva y materialmente justa, en conjunción con los otros valoresy principios reconocidos por la Constitución Política del Estado, de tal manera que la sentencia concrete tales valores y principios, esencialmenteel valor superior del ordenamiento jurídico, como es la justicia" (Casación No 864-2007 Huaura, Sala Civil Transitoria de la Corte Suprema, sentencia del 22-10-07).

LaCorteSupremaTambién ha reconocido al debido proceso como un derecho humano y fundamental que comporta un juzgamiento imparcial y justo con un mínimo de garantías procesales de jerarquía constitucional:

\footnotetext{
"Que, en la doctrina se ha conceptuado el debido proceso o proceso justo como un derecho humano o fundamental quetiene toda persona por el sólo hecho de serlo, y que le faculta a exigir al Estado un juzgamiento imparcial y justo ante un Juez responsable, competente e independiente, toda vez que el Estado no sólo está en el deber de proveer la prestación jurisdiccional a las partes o terceros legitimados, sino a proveerla bajo determinadas garantías mínimas que le aseguren tal juzgamiento imparcial y justo." (CAS. 2544-2005 (JUNíN) Sala Civil Transitoria dela CorteSuprema).
}

En consecuencia, el Tribunal Constitucional y la Corte Suprema, como se advierte de las resoluciones anotadas han establecido que el derecho a la tutela jurisdiccional efectiva comprende derechos específicos como el 
Víctor Ticona Postigo - El debido proceso y las líneas cardinales para un modelo procesal en el Estado Constitucional de Derecho

derecho de acceso a la justicia y al proceso, el derecho al debido proceso y el derecho a la efectividad y eficacia de las sentencias y resoluciones homologatorias.

No está demás recordar que el Tribunal Constitucional ha reconocido el debido proceso en sede administrativa y al interior de las corporaciones particulares; en esteúltimo caso como expresión dela eficacia horizontal de los derechos fundamentales. Así mismo, ha reconocido el debido proceso sustantivo o material, cuyo contenido básicamente de refiere al principio de razonabilidad; el cual también es exigiblea todos los poderes públicos como a los particulares ${ }^{23}$.

\section{CONCLUSIONES}

Como corolario de las líneas que anteceden podemos concluir que:

A. Nuestro sistema jurídico-político, por lo menos formal mente, responde a las características de un Estado Constitucional de Derecho por cuanto contamos con una Constitución rígida, se regula y limita el ejercicio del poder público y se reconoce y garantiza los derechos fundamentales, a través de cierto tipo de "garantías" que van desde las garantías judiciales a las institucionales.

B. Uno de los elementos esenciales del Estado de Derecho es la Tutela Jurisdiccional y la vertienteprocedimental delos derechos fundamentales.

C. Así mismo la efectividad del debido proceso es un factor que promueve el sistema democrático y para su consol idación debepromoverse la tutela supraconstitucional del proceso a través del reforzamiento de la legitimidad de los organismos internacionales.

D. El debido proceso y la Tutela Jurisdiccional efectiva están reconocidos por nuestra Constitución Política, por consiguiente, sin desconocer su origen, debe compatibilizarse y conjugarse su configuración y ejercicio, de tal modo que el ejercicio de uno no excluya el del otro y, en tal sentido, que siendo derechos que tienen una relación dialéctica, se optimizan en el ejercicio armónico de ellos. El debido proceso, en sede judicial, está contenido dentro del Derecho a la Tutela Jurisdiccional Efectiva. 
Víctor Ticona Postigo - El debido proceso y las líneas cardinales para un modelo procesal en el Estado Constitucional de Derecho

E. El debido proceso formal y el debido proceso sustancial no son 2 derechos sino 2 aspectos del debido proceso, o mejor dicho aún, dos aspectos del proceso justo.

F. Quenuestra normatividad dedesarrollo cortinal ha reconocido el debido proceso en diversas normas procesales. Excepcionalmente se ha reconocido en el Código Procesal Constitucional el derecho a la Tutela Procesal Efectiva, derecho que comprendería el acceso a la justifica y el derecho del proceso.

G. La CorteSuprema a reconocido en forma amplia los elementos del debido proceso, tanto en su dimensión procesal como en su dimensión material. En esta última postula quela quela decisión a recaer en un proceso debe ser objetiva y material mentejusta. El Tribunal Constitucional reconoció también el debido proceso, con elementos de carácter procesal y en su dimensión sustantiva, configurando esta última dimensión como un contenido esencial: el derecho a una decisión razonable, criterio con el cual no compartimos.

H. Un model o constitucional sobreel Debido Proceso, puedeser concebido en dos sentidos: 1) en el sentido estricto, cuando la Constitución reconoce solamente el ementos comunes del debido proceso aplicables a todo tipo de proceso jurisdiccional; 2) en el sentido amplio, si la Constitución además de reconocer estos el ementos comunes también reconoce otros elementos aplicables solamente en ciertos procesos, como es el caso del proceso penal, en donde hay unos el ementos queleson propios, como el derecho a no autoinculparse, el derecho a guardar silencio, entre otros.

1 La Constitución española reconoce los Ilamados valores superiores del derecho y en Art. 1.1. precisa: "España se constituye en un Estado social y democrático de Derecho, que propugna como valores superiores de su ordenamiento jurídico la libertad, la justicia, la igualdad y el pluralismo político". Por otra partes, compartimos la propuesta de Miguel Ángel Villalobos Caballero, quecon relación a los valores jurídi cos afirma "Consideramos que existen varios valores en el Derecho como ya lo hemos anotado, pero sólo existe un valor supremo que es la justicia", La Finalidad del D erecho, Lima, Editora RAO Jurídica S.R.L. 2004, p. 100.

2 Lucas Verdú, P. Curso de D erecho Político, Vol. II, 3ra edición Tecnos S.A. Madrid 1986, pp.238 y ss. citado por Mendoza Escalante, Mijail, Los Principios Fundamentales del Derecho Constitucional Peruano, Lima, 2000, p.179. 
Víctor Ticona Postigo - El debido proceso y las líneas cardinales para un modelo procesal en el Estado Constitucional de Derecho

3 Mendoza Escalante, M., Ob. Cit.... p.180.

4 Aguiló Regla, J. La Constitución del Estado Constitucional, Palestra-Temis, Lima-Bogotá, 2004 p. 53.

5 Benda, Maihofer, Vogel, Hesse, Heyde, M anual de D erecho Constitucional, segunda edición, Madrid Barcelona, Marcial Pons, Ediciones Jurídicas y Sociales S.A. 2001. pp. 493 y ss.

6 Cfr. Mendoza Escalante, Ob. Cit., ...p. 180 y ss.

7 Gil Domínguez, A., Tutela Judicial efectiva y A gotamiento de la vía administrativa, lera. Edición-Buenos Aires, editorial Ad Hoc 2007, p. 31 y 36.

8 Hoyos, Arturo, D ebido Proceso y D emocracia, lera edición, México, editorial Porrúa, 2006, p. 31 y ss.

9 Ob. Cit. P. 163

10 Fundamentos del D erecho Procesal Civil, 4ta edición, Montevideo-Buenos Aires, Editorial B de F, 2002, p. 120, 122.

11 El término tutelajurisdiccional efectiva al parecer no tienesu origen en el Derecho Español con el artículo 24ㅇ de la Constitución de 1978, por ser la norma que di o difusión a esta institución de mucha importancia actualmente en el Derecho Procesal, no obstante Peyrano citando a Rafael Ortiz señala que la locución preañada de significados "tutela judicial efectiva" no nació con la promulgación del siempre citado artículo 24이 de la Constitución española de 1978 ni con la sanción del artículo 8 dela Convención A mericana de Derechos Humanos, sino con la redacción del art. 24ㅇ de la Constitución Italiana de 1947 y con la confección de los artículos 19.4 y 103.1 de la Ley Fundamental deBonn de 1949. Hurtado Reyes, Martín, Tutela Jurisdiccional D iferenciada, lera. edición, Lima, Palestra editores, 2006, p. 36, 37 y 38.

12 Los D erechos Humanos, el D ebido Proceso y las Garantías Constitucionales de la A dministración de Justicia, en: La Constitución Peruana de 1979 y sus Problemas de A plicación, Director Egiguren Praeli, Francisco, Lima Editorial Cuzco S.A. Editores, 1995, pp. 110-112.

13 Estudios de la Constitución Política de 1993, Tomo V, Pontificia Universidad Católica del Perú Fondo Editorial 1999, p. 65.

${ }^{14}$ Cfr. Introducción al Proceso Civil, tomo I, Santa Fe de Bogotá Colombia, Temis - De Belaunde \& Monroy, 1996 pp. 245 y 247.

15 El D erecho a la Jurisdicción antes del Proceso, Buenos Aires, Ediciones Desalma, 1984 p.47.

16 Ob. Cit. p. 247

17 Ob. Cit. pp. 245 y 246

18 Régimen Legal y Jurisprudencia del A mparo, Buenos Aires, Editorial Ediar, 1969, p. 17.

19 Bustamante Alarcón, R., D erechos Fundamentales, lera. edición Lima, Ara editores, 2001

20 L.P. Comoglio y A. M. M orello, Presidencias del Instituto Iberoamericano de Derecho Procesal: Dr. Omar Berizonce La Plata, A rgentina, 2000-2004); Pairo Parra Quijano (Bogotá, Colombia, 2004) en: Augusto M . Morello, El Proceso J usto, Librería Editora La Plata y LexisN exis A bel edo-Perrot, segunda edición, p. 785.

${ }^{21}$ Gozaíni, Osvaldo Alfredo. Derecho Procesal Constitucional, El D ebido Proceso, Buenos Aires, RubinzalCulzoni Editores, 2004, pp. 40 y 41. En el mismo texto se cita partede la resolución en dondela Corteha sosteni do que el derecho a un recurso efectivo resulta ilusorio cuando en la realidad resulta inútil por la ausencia o defectos en las garantías constitucionales que todo proceso debe tener: "La Corte amplia los míni mos involucrados en este aspecto, al sostener que los recuro son ilusorios cuando se demuestra su inutilidad práctica, el Poder Judicial carece de la independencia necesaria para decidir con imparcialidad o faltan los medios para ejecutar las decisiones quese dictan en ellos. A esto puedo agregarse la denegación dejusticia, el retardo injustificado dela decisión y el impedimento del acceso del presunto lesionado al recurso judicial (caso Ivcher Bronstein, sentencia del 06.02.2001)".

22 El modelo Constitucional de juicio justo en el ámbito del proceso civil, Barcel ona, editorial A telier, 2002, p. 66.

23 Encontrándonos en vías de reforma constitucional, en el tema de Justicia, sería la oportunidad para reafirmar el reconocimiento explícito del derecho al debido proceso en sus dos dimensiones; el formal y el sustantivo o material, con el contenido y al cances que se ha establ ecido en la jurisprudencia ya anotada del Tribunal Constitucional y de la Corte Suprema. 